\title{
ОБ АКТУАЛЬНЫХ ПРОБЛЕМАХ ЭКОНОМИЧЕСКОГО РАЗВИТИЯ, НЕРАВЕНСТВЕ И ЕГО ВЛИЯНИИ НА НАШУ ЖИЗНЬ
}

\author{
Варшавский A.E.
}

В работе рассмотрены вопросы, связанные с углублением проблем сочиально-экономического и научно-технологического развития России в результате кризиса, вызванного эпидемией коронавируса, в том числе проблем, связанных с национальной безопасностью. Особое внимание уделено проблемам значительной деиндустриализачии, а также проблемам, связанным с ичифровизачией. Показана необходимость совершенствования экономической политики и кредитно-финансовой системы. Рассмотрены также вопросы микроэкономического характера, в первую очередь, проблемы чрезмерного неравенства доходов и пространственного неравенства, оченены ресурсы, которые можно получить в результате перераспределения доходов; рассмотрено негативное влияние неравенства доходов на музыкальное искусство. Показана необходимость совершенствования управления, недопустимость проблемных инноваций, в том числе в сферах образования, науки и здравоохранения, а также актуальность развития системь индикативного планирования.

DOI: $10.20537 /$ mce2021econ02

Введение. В работе, основанной на тезисах пленарного доклада на Международной конференции «Математика. Компьютер. Образование» (МКО), проходившей в Пущино в январе 2021 г., рассмотрены вопросы, связанные с углублением проблем социальноэкономического и научно-технологического развития России в результате кризиса, вызванного эпидемией коронавируса, в том числе проблем, связанных с национальной безопасностью. Особое внимание уделено проблемам значительной деиндустриализации, цифровизации. Рассмотрены вопросы микроэкономического характера, в первую очередь, проблемы чрезмерного неравенства доходов и пространственного неравенства, оценены ресурсы, которые можно получить в результате перераспределения доходов. Показана необходимость совершен- 
Вариавский А.Е. Об актуальных проблемах экономического развития.., стр. 22-37

Varshavsky A.E. On the current problems of economic development..., pp. 22-37

ствования управления. недопустимость проблемных инноваций, в том числе в сферах образования, науки и здравоохранения, а также актуальность развития системы индикативного планирования.

Кризис обострил проблемы социально-экономического и научно-технологического развития России. Ориентация на либерализацию экономики, нацеленность прежде всего на получение прибыли, сверхбыстрое распределение общественной собственности, резкое усиление дифференциации доходов населения - все это многократно повысило и повышает риски, вызываемые кризисом. Введение санкций еще более усугубило ситуацию.

Коронавирус является одним из аспектов неизбежного продолжения и усиления мирового экономического кризиса.

Возможные последствия кризиса необходимо предвидеть: после завершения активной фазы борьбы с коронавирусом начавшаяся во всем мире деглобализация, характеризующаяся процессами решоринга, должна еще более усилиться; одновременно следует учитывать возрастание нестабильности во всем мире, что предъявляет особые требования к обеспечению национальной безопасности.

Политические проблемы. Национальная безопасность. Следует учитывать прогнозы, особенно после или во время кризисов. Это не конспирология. Прогнозы могут читать агрессивные личности, в том числе президенты, их помощники и помощницы, военные, которым хочется повоевать. Из этих прогнозов агрессоры могут брать идеи, которые потом начнут претворять в жизнь. Надо учитывать и страны - потенциальные агрессоры.

Можно привести в качестве подтверждения сказанного два прогноза.

1-й прогно3 - прогноз пандемии (для большей убедительности приведем цитату на языке оригинала): Scenarios for the Future of Technology and International Development. The Rockefeller Foundation and Global Business Network. May 2010 (p.18) [1]: «In 2012, the pandemic that the world had been anticipating for years finally hit... this new influenza strain ....was extremely virulent and deadly. ...the virus streaked around the world, infecting nearly 20 percent of the global population and killing 8 million... The pandemic also had a deadly effect on economies: international mobility of both people and goods screeched to a halt, debilitating industries like tourism and breaking global supply chains.... shops and office buildings sat empty for months, devoid of both employees and customers... During the pandemic, national leaders around the world flexed their authority and imposed airtight rules and restrictions, from 
the mandatory wearing of face masks to body-temperature checks at the entries to communal spaces like train stations and supermarkets». (Сценарии будущего развития технологий и международного развития. Фонд Рокфеллера и Глобальная деловая сеть. Май 2010 (с. 18): «В 2012 году пандемия, которую мир ожидал в течение многих лет, наконец, разразилась... этот новый штамм гриппа ... был чрезвычайно вирулентным и смертельным. ...вирус распространился по всему миру, заразив почти 20 \% мирового населения и убив 8 млн человек... Пандемия также оказала смертельное воздействие на экономику: международная мобильность как людей, так и товаров резко снизилась, негативно сказываясь на таких отраслях, как туризм, и разрушая глобальные цепочки поставок ... магазины и офисные здания пустовали месяцами, лишенные как сотрудников, так и клиентов....Во время пандемии национальные лидеры во всем мире усилили свою власть и ввели жесткие правила и ограничения, начиная с обязательного ношения масок для лица и заканчивая проверкой температуры тела при входе в общественные места, такие как железнодорожные вокзалы и супермаркеты»).

В этом прогнозе, 10 лет тому назад, были описаны события, связанные с коронавирусом - и ношение масок, и измерение температуры, причем на 19.06.2021 г. скончалось более 1.6 млн человек.

2-й прогноз - прогноз захвата Турцией территории России, - приведен в 2009 г. в книге Фридмана Д. «Следующие 100 лет: прогноз событий» [2], где прогнозируется значительное повышение активности Турции и захват ею к 2050 г. южной части России примерно до Волгограда (на c. 269 этой книги представлена карта, на которой турецкой обозначена территория, включающая Крым, Каспийское море, Астрахань. Волгоград).

Необходимость совершенствования экономической политики и кредитно-финансовой системы. Экономические цели должны быть подчинены задачам укрепления национальной безопасности и повышения социального благосостояния. Можно выделить следующие проблемы в результате проводившейся политики.

Валовое сбережение значительно превышает валовое накопление валовое накопление основного капитала.

Чрезмерное неравенство доходов - как до 1917 г., чрезмерное пространственное неравенство.

Ориентация на экспорт сырья, продукции первых переделов и импорт оборудования и технологий. Глубокая деиндустриализация экономики; значительная зависимость производственного потенциала 
страны от зарубежной техники и технологий. Низкая доля обрабатывающей промышленности (ОП) в ВДС [3].

Высокая стоимость кредита для предприятий. Ориентация коммерческих банков на максимизацию прибыли.

Значительная недооценка человеческого капитала. Снижение качества образования, недофинансирование науки.

Отсутствие внутреннего спроса со стороны экономики на отечественные достижения в сфере научных исследований и разработок и др. Отсутствие понимания того, что Россия, как и любая другая страна, не может быть первой во всех областях науки и технологии, т.е. многое должна заимствовать за рубежом (можно привести слова выдающегося ученого; вице-президента АН СССР академика В.А. Котельникова: «В электронике мы действительно отстаем. Отстаем и в области информационных технологий. Но мы должны их вести, если мы хотим быть самостоятельной страной» [4]).

Не учитываются рекомендации ученых и специалистов органами государственного управления.

Вывоз капитала в оффшоры. В качестве примера деиндустриализация можно привести данные об. автомобильном экспорте Турции в Россию, который составляет около 500 млн евро, в том числе $20 \%$ - готовые автомобили, а остальное - автокомпоненты (аккумуляторные батареи, автостекло, стеклоочистители, кузовные панели, радиаторы, фильтры, пружины, топливная аппаратура, детали подвески, пластмассовые и алюминиевые детали, детали и узлы для систем сцепления и тормозной системы и др.). Так на предприятие Ford-Sollers в Татарстане для производства автомобиля Ford Transit основное число автокомпонентов, узлов и деталей поставляется из Турции. Ряд турецких компаний инвестируют в производство автокомпонентов в России (например, одна из них инвестирует в собственное предприятие в Татарстане. Потребители КАМАЗ, АвтоВА3, Volkswagen, Renault и др., основная продукция - кузовные детали, производство расширяется [5]. Очевидно, при таком разделении труда между странами нельзя говорить о роботизации в России.

Проблемы значительной деиндустриализации. Доля промышленности существенно снизилась: в ВВП с $35.4 \%$ (1990 г.) до 23.6\% (2016 г.), в выпуске - с 48.6\% (1990 г.) до 37.7\% (2016 г.). Значительный спад произошел в станкостроении: в 1990 г. в России, по данным Росстата, выпускалось 74,2 тыс. МРС, в том числе с ЧПУ - 16.7 тыс., в 2011 г. - 3.2 и 0.2 тыс., соответственно, и в 2017 г. - 4.4 тыс. МРС. 
Место России по объему производства ряда наукоемких отраслей среди 53 стран (2012 г.): электронная техника и оборудование в целом 30-е место; компьютеры - 26-е; офисное оборудование - 13-е; оборудование для контроля и приборы - 28-е; медицинское и промышленное оборудование - 24-е; оборудование для радиосвязи и радары - 34-е; телекоммуникационное оборудование - 30-е; потребительская техника 17-е; компоненты (пассивные компоненты, полупроводники и пр.) - 30-е. Среди 12 восточноевропейских стран: по объему производства электронной техники у нас 5-е место (5536 млн долл.), уступая Венгрии (14968 млн долл.), Чехии (13565 млн долл.), но на рынке электроники из-за значительных объемов импорта Россия в несколько раз опережает эти страны [6].

Значительное отставание в области высоких технологий. Пример промышленные роботы (ПР). В СССР было выпущено более 100 тыс. ПР (заменили более 1 млн рабочих), за 1992-1994 гг. почти все выбыли. Парк роботов в России - 5 тыс. в 2004 г., в 2015 г. - 8 тыс. В 2018 г. в России было продано 860 ПР, только 5\% из них - отечественного производства; плотность роботизации — на 10 тысяч занятых — 5 ПР (в ЕС - 106, США - 91, в Азии - 75). По числу продаваемых роботов в год Россия находится на 27 месте в мире. Рост парка ПР требует восстановления и дальнейшего развития производств ОП - основных потребителей ПР [7].

Проблемы цифровизации: концентрация внимания на сфере услуг. В условиях деиндустриализации — неизбежно переключение внимания на цифровизацию не сферы материального производства, а сферы услуг. «В России понятие «цифровизация» в настоящий момент сконцентрировано исключительно на создании новых видов сервисов, базирующихся на сборе и анализе данных с различных физических объектов... И не охватывает вопросы кардинального изменения ситуации в производственной системе, подходов к проектированию, производству, сбыту и эксплуатации этих физических объектов, что заложено в концепцию Индустрии 4.0» [8].

Можно дать два примера: положительный (1) и отрицательный (2).

Пример 1. Промышленность: модернизация информационной инфраструктуры электроэнергетики, сбор и анализ данных об объектах отрасли с широким использованием облачных технологий и достижений в области ИИ (формирование баз знаний для быстрого и качественного принятия решений; управление большими объемами данных; интеллектуальная аналитика; кибербезопасность; моделирование; иерархическое управление и т.п.). 
Пример 2. Услуги, экспорт: Российская компания Smart Engines (занимается разработкой решений для распознавания символов и документов в видеопотоке и на изображениях, проводит исследования в области машинного обучения, высоконагруженных систем и алгоритмической оптимизации) разработала модуль для мобильного приложения, используемого легальными секс-работниками Германии, который распознает сертификаты регистрации проституток и затем автоматически заполняет формы в приложении [9] (вряд ли такую деятельность можно назвать достойной).

Следует напомнить и о том, что многие эксперты не видят больших перспектив для ИКТ через 10-15 лет [10].

Микроэкономика. Чрезмерное неравенство доходов. О неравенстве доходов свидетельствуют следующие данные.

По оценкам специалистов, индекс Джини превышает 47 (по данным Росстата, в РФ - 42 (2014 г.), 41.2 (2016 г.), в Москве - 45.2 (2014 г.), 42.1 (2016 г.); следует отметить, что данные Росстата занижены. В СССР индекс Джини был значительно ниже - 23.8 (1989 г.) [11-15].

Регрессивная ставка ЕСН (в 2019 г.: 30.2\% при заработной плате от 0 до 865000 руб.; 27.3\% свыше $865000 ; 15.3 \%$ более 1150000 руб. в год).

Соотношение Джини до и после уплаты НДФЛ: страны ЕС $1.45-1.84$; США - 1.31; Россия: $\approx 1.0$, т.е. у нас фактически нет перераспределения, - НДФЛ и трансферты не снижают неравенство. При этом увеличение доли доходов $1 \%$ наиболее богатых на 1 п.п. приводит к сокращению отношения коэффициентов Джини до и после выплаты налога на 0.085 [16].

О многом свидетельствует сопоставление с уровнем затрат на питание бездомной собаки и кошки в сравнении с ПМ. В Москве на собаку было нужно 5500 руб./мес. в 2019 г. (4950 руб./мес. в 2012 г.) и на кошку - 3614 руб./мес. (2012 г.). ПМ в Москве (III квартал 2019 г.): на душу населения был равен 17329 руб.; для трудоспособного населения 19797 руб.; для пенсионеров - 12253 руб.; для детей — 14889 руб., т.е. ПМ пенсионера равен 2.2 ПМ собаки. При этом ПМ в России (2019 г.) составлял 11185 руб. для всего населения, 12130 руб. для трудоспособного населения, для пенсионеров - 9236 руб., для детей - 11004 руб. В 2011 г. на стерилизацию собак и содержание их в приютах из городского бюджета Москвы было выделено 780 млн руб. (наиболее дешевый проект строительства подобных приютов стоит 10 млн руб.); на отлов и временное содержание в муниципальных приютах Москва ежегодно расходует порядка 934.7 млн руб. - по 7.5 млн на 100 тыс. населения [17] 
(недавно были приняты поправки в Конституцию и Россия стала второй страной мира после Германии, в которой основной закон страны защищает животных; в прежней Конституции не было обозначено ответственного обращения с ними) [18].

Для сравнения: на 2016 г. по подпрограмме «Развитие отечественного станкостроения и инструментальной промышленности на 20112016 гг.» намечалось на НИОКР - 2580 млн руб. и на капвложения 1500 млн руб. [19, 20].

Пространственное неравенство. Доля Москвы и Московской области в доходах консолидированного бюджета превышает $25 \%$, в том числе по налогу на прибыль организаций свыше $32 \%$ и НДФЛ также около $32 \%$. Доля населения Москвы - 8.66\%, Московской области $5.27 \%$ и в целом Московской агломерации - 13.93\% (на 1.01 .2021 г.), однако реальные данные, по оценкам значительно выше, причем прогнозируется дальнейший рост населения, что крайне негативно влияет на национальную безопасность, создавая проблемы, связанные с территориальной целостностью страны.

В 2020 г. налоговые доходы бюджета Москвы составили 2.254 трлн руб., НДФЛ - 1130 млрд руб. (50.1\% налоговых доходов), в Москве в 2014 г. на 20\% наиболее богатых приходилось 50.3\% всех доходов (коэффициент фондов - 20.9 и коэффициент Джини - 45.2 по данным Росстата). Повышение ставки для 20\% наиболее богатых с $13 \%$ до 26\% привело бы к росту дохода от НДФЛ примерно на 565 млрд руб.

Для сравнения: дефицит бюджета Пенсионного фонда России в 2018 г. составил 256.8 млрд руб. Можно дать пособие при рождении на каждого ребенка в России (1.6 млн в 2018г.) - около 350 тыс. руб. (сейчас единовременное пособие при рождении ребенка - 18886.32 руб. — с 1.02.2021 г.); объем финансирования учреждений РАН около 90.4 млрд руб. [22-24].

Чрезмерное территориальное неравенство предопределяет и отношение к москвичкам. Так, даже бывший министр С.Б. Иванов, бывший житель Ленинграда, писал: «Вообще житель Москвы — понятие условное. Что такое жители Москвы? Это дворники, водители, офисный планктон, журналисты...чиновники, сфера обслуживания, торговля. В крайнем случае блогеры. Что эта 15-20-миллионная масса производит? Ровным счетом ничего. Интеллектуальную собственность? Вопрос сомнительный» [21]. И это про Москву, где сосредоточено около 1/3 научного потенциала России!? 
Отметим также негативное влияние неравенства доходов на музыкальное искусство. Слушание классической музыки, ее восприятие требует определенных усилий и подготовленности, Посещение концерта классической музыки требует внимания и понимания прослушиваемого.

В СССР существовала целостная централизованная система государственной поддержки концертной деятельности, развития музыкальной культуры. С переходом к рыночным отношениям, произошло скачкообразное повышение неравенства: сформировался значительный слой бедного населения, возросло пространственное неравенство, изменились условия государственной поддержки и организации концертной деятельности и др. Значительный рост цен на билеты не позволяет любителям живой музыки регулярно и часто посещать концерты и представления, как прежде. Соответственно, стало затруднительным обеспечить спрос со стороны молодежи на концерты симфонической музыки.

Облегчение восприятия музыки за счет ее упрощения способствует привлечению музыкально менее образованных слушателей на концерты, позволяет повысить спрос на концерты и музыкальные представления, снижая качество исполняемых произведений. Это ведет к серьезному риску вытеснения классической музыки. Можно привести слова В. Ашкенази: «Гораздо легче слушать... поп-звезд, потому что процесс восприятия этой музыки не требует никаких усилий, ни умственных, ни духовных. Да и эмоции она затрагивает самые примитивные» [25].

Музыка благотворно действует на человека, существует музыкотерапия. Но требуется защита от звуковых колебаний с частотами, совпадающими с резонансными частотами органов человеческого тела: 2030 Гц - резонанс головы, 40-100 Гц - глаз, 0.5-13 Гц - вестибулярного аппарата, 4-6 Гц - сердца, 2-3 Гц - желудка), 2-4 Гц - кишечника), 6-8 Гц - почек, 2-5 Гц - резонанс рук. Влияет и интенсивность звука - на концертах поп- и рок музыки сила звука вблизи сцены 120 дБ (сила звука реактивного двигателя).

Доступная для неподготовленного слушателя музыка: попса, хипхоп, рок, тяжелый рок, - основана именно на низких частотах — ритм около 2 Гц, получают распространение музыкальные формы с ритмом около 4 Гц, которые наносят вред головному мозгу, печени, желудочнокишечному тракту, действует на сердечно-сосудистую, иммунную и нервную системы. Под влиянием слишком громкой музыки соответствующего ритма толпа часто становится агрессивной $[25,26,27]$. 
Совершенствование управления. Недопустимость проблемных инноваций в управлении. Ограниченность имеющихся средств ведет к стремлению органов государственного управления экономить, для чего проводятся реформы с помощью подходов, как правило, заимствованных за рубежом и не учитывающих специфику развития России (экономический спад в результате перехода к рынку, затянувшееся преодоление последствий шоковой терапии и др.). Основное внимание при этом уделяется количественным показателям.

В данном случае можно говорить об обезьянстве (слепом подражании), о проблемных инновациях в управлении, которые характеризуются тем, что наносят вред объекту управления, причем этот вред может быть значительным (подробнее о проблемных инновациях см. [28, 29].

\section{Проблемы реформирования в социальной сфере, имеющей от- ношение к развитию человеческого капитала.}

Образование. Реформаторы считают, что образование и здравоохранение - это услуги, которые востребованы на протяжении всей жизни человека, они мечтают снять нагрузку с государства, так как, по их мнению, должны возрасти частные расходы на развитие человеческого капитала, они оптимистически возлагают надежды на новые технологии, особенно на цифровизацию, которые должны радикально изменить характер услуг, способствующих повышению человеческого капитала.

Коронавирус им в этом, безусловно, помогает: инноваторы заявили об успешном опыте перевода образования в школах и вузах России на дистанционную форму с помощью цифровых технологий, который, по их мнению, должен стать «эталоном» для системы образования в России в будущем.

При этом считается, что образование - услуга, за нее надо получать побольше денег.

Все эти реформы и предложения, как правило, заимствованы за рубежом без серьезного анализа их негативных последствий и в условиях низкого финансирования образования, преследуют второстепенные цели, ведут к существенному снижению качества образования, особенно в последние годы после введения бакалавриата и практически полного отказа от специалитета. Так, по мнению создателей Болонской системы, программа обучения должна быть индивидуальной, состоять из модулей, которые «можно получать в других университетах, в том числе и в зарубежных». Но у нас не учитывается, что Болонская концепция нацелена на приток молодежи в свои страны, т.е. отток из России. 
Результат - снижение качества образования: соотношение принятых в ВУЗы к получившим дипломы о среднем (полном) общем образовании в 1993 г. составляло 59.8\%, а в 2002 г. - 88\% получивших диплом о среднем (полном) общем образовании в году t к получившим диплом об основном общем образовании в году $\mathrm{t}-2$ с $52.1 \%$ до $65.2 \%$; соотношение выпуска из ВУЗов в году t к принятым в ВУЗ в году t-5 в СССР и в России 1970 -х гг. составляло около $80 \%$ и в конце 1980 -х гг. около $70 \%$, оно увеличилось до $92.5 \%$ в 2002 г., 92.9\% в 2015 г. [31,32]. При этом если выпуск специалистов с высшим образованием на 10000 занятых в экономике в 1993/1994 г. составлял 63 человек, то в 2013/2014 г. он возрос до 181 человек (максимум в 2010/2011 г. - 217 человек).

Сфера науки. Руководство Минобрнауки РФ отмечало в 2008 г.: устойчивое развитие сдерживается из-за низкой производительности труда в образовании, в науке, наукоемких отраслях, и поэтому для модернизации и повышения эффективности экономики необходима оценка результативности деятельности учреждений науки, а также образования [30].

Для этого стали использоваться не экспертные, а количественные библиометрические показатели. Следует сказать, что библиометрия стала применяться для оценки результативности научных работников в университетах США с целью контроля за выделяемыми из федерального бюджета большими средствами - в конце 1980-х гг. субсидии университетам США на НИОКР были увеличены более чем в 2 раза и в погоне за ними вузы начали пренебрегать преподаванием и «даже стали культивировать науку сомнительного качества» (в университетах США 29\% всех исследователей, но 75\% всех научных публикаций, 2016 г.). Однако в России эти методы вводятся не только для вузов, но и для научных институтов РАН, где проводятся только научные исследования. За рубежом специалисты отмечают: библиометрические методы используются неправильно, это очень вредно для науки. Необходимо, чтобы анализ цитирования был дополнением к экспертной оценке, а не ее заменой.

Сфера здравоохранения. Старение населения, появление новых лекарств, рост цен на медикаменты повышают затраты на медицинское обслуживание. Во многих странах медицинские организации объединяются с целью экономии. По примеру других стран в России с 2000 г. число медицинских учреждений уменьшилось на $60 \%$; численность больничных организаций сократилась с 12.8 тыс. в 1990 г. до 5.3 тыс. в 2017 г., что меньше, чем в 1932 г. (5962 больницы), численность врачей санитарнопротивоэпидемической группы и врачей по общей гигиене составила 27.8 
тыс. человек в 2000 г. и 13.6 тыс. человек в 2017 г. (это снижение ощутилось при пандемии коронавируса), терапевтов - 159.2 тыс. человек и 168.8 тыс. человек, педиатров - 72.1 тыс. человек и 60.0 тыс. человек; психиатров и наркологов - 23.6 тыс. человек и 22.1 тыс. человек; дерматовенерологов - 11.4 тыс. человек и 11.7 тыс. человек; фтизиатров - 9.9 тыс. человек и 8.0 тыс. человек; врачей по лечебной физкультуре и спортивной медицине - 4.4 тыс. человек и 4.0 тыс. человек, соответственно.

Все это было сделано по примеру США, где за 10 лет произошло 640 слияний больниц, Великобритании (объединение почти половины больниц) и т. д., хотя там качество медицинского обслуживания от этого не улучшилось. Но в 2016 г. общие расходы на здравоохранение составляли: в России 5.3\% ВВП, в Великобритании - 9.8\%, Франции $11.5 \%$, США - 17.1\% ВВП). В России частные расходы на медицину возросли на 104\% в 2005-2018 гг., всего, а расходы на платные медицинские услуги на $121 \%$ (государственные расходы на здравоохранение в среднем составляют $3.5 \%$ ВВП). Ситуация, связанная с коронавирусом в 2020 г., подтверждает существование значительных проблем из-за нехватки медицинских учреждений и больничных коек [33].

Направления совершенствования управления. Необходимо подчинение развития экономики целям более высокого порядка: повышение благосостояния людей; создание условий для максимального раскрытия возможностей, заложенных в каждом человеке, в том числе для самосовершенствования на основе расширения знаний и повышения уровня культуры; обеспечение национальной безопасности и т.д.

Необходим пересмотр принципов либерального капитализма: нацеленность только на получение максимальной прибыли при отсутствии соответствующих законов облегчает расширение эгоистических тенденций, ведет к забвению морально-этических норм везде, где слабо развито правовое поле, и в итоге к усилению неравенства общества в целом.

Для социально-экономического развития, перехода к социальноориентированной экономике необходимы: ориентация на цели долгосрочного развития, а не на быстрое получение прибыли; разработка и реализация долгосрочной комплексной программы научно-технологического развития страны; приоритетное развитие сферы науки, образования, ОП, инвестиционного комплекса, социальной сферы и др.; пересмотр отношения к дефициту бюджета, укрепление рубля (в январе 2021 г. курс по Биг-Маку составлял 23.85 руб./долл.., а на валютном рынке - 70.6 руб./долл. в июле 2020 и 73.55 руб./долл. 16.01.2021 г., т.е. рубль недоценен на 68\%); наце- 
Вариавский А.Е. Об актуальных проблемах экономического развития.., стр. 22-37

Varshavsky A.E. On the current problems of economic development..., pp. 22-37

ленность бюджетно-налоговой политики на реальную модернизацию экономики; прогрессивное налогообложение; значительное снижение ставки рефинансирования; эмиссия «длинных денег» (государственные ценные бумаги); жесткий контроль вывоза капитала, деофшоризация, ограничения на трансграничное движение спекулятивного капитала; увеличение монетизации экономики для поддержания внутреннего спроса (сейчас около $45 \%$; повышение доли в ВВП инвестиций в основной капитал примерно в 1.5 раза; снижение налоговой нагрузки на инновационную деятельность, дифференциация ставок кредитования в соответствии с приоритетами развития; использование нефтегазовых доходов бюджета на закупку критически необходимых импортных технологий; отход от политики обеспечения профицита бюджета; использование средств ФНБ для развития экономики; осуществление политики протекционизма, восстановление экспортных тарифов на сырье и импортных тарифов на готовую продукцию и т.д.

Развитие системы индикативного планирования. Для ускорения социально-экономического развития необходима разработка аналога Комплексной программы НТП (КП НТП) в системе государственного планирования. Следует учитывать значительные масштабы работ по КП НТП: в работе над КП НТП принимали участие примерно 2 тыс. ученых, специалистов и практиков, которые представляли более 500 научноисследовательских, проектных и конструкторских организаций. Например, в 3-й КП НТП, помимо сводного документа и 5 сводных отдельных разделов по основным направлениям развития науки, НТП, важнейшим проблемам социально-экономического развития, региональным и международным проблемам, было 50 отдельных разделов (8 разделов по направлению “наука", 17 - “технический прогресс", 7 - по направлению “экономика", 15 региональных и 3 международных раздела). Такую работу нельзя выполнить силами 2-3 приправительственных вузов и, тем более, одного центра. При этом должен быть обеспечен высокий уровень управления КП НТП. Так, в СССР общий контроль за выполнением работ по КП НТП был возложен на Научный совет по проблемам научнотехнического и социально-экономического прогнозирования АН СССР и ГКНТ и соответствующие комиссии Совета, его председателем был выдающийся ученый вице-президент АН СССР академик В.А.Котельников (заместители председателя: академик А.И. Анчишкин и заместитель председателя ГКНТ С.М. Тихомиров). На разных этапах к работе над программой подключались президенты Академии наук СССР — вначале академик М.В. Келдыш, а впоследствии - академик А.П. Александров [34]. 


\section{СПИСОК ЛИТЕРАТУРЫ}

1. Scenarios for the Future of Technology and International Development. The Rockefeller Foundation and Global Business Network. May 2010.

2. Friedman $G$. The Next 100 Years: A Forecast for the 21 st Century. New York: Doubleday, 2009 / Фридман Д. Следующие 100 лет: прогноз событий XXI века. М.: Эксмо, 2010.

3. Варшавский А.Е. Проблемы социально-экономического развития страны после завершения активной фазы борьбы с коронавирусом // Научно-практический журнал "Концепции". 2020. №1(39). DOI: 10.34705/КО.2020.39.1.001

4. Варшавский A.E. О Владимире Александровиче Котельникове / в книге В.А. Котельников. Судьба, охватившая век. Т.1 Воспоминания коллег. М.: ФИЗМАТЛИТ, 2011, с. 294-299.

5. Как под боком у России вырос турецкий автогигант. А мы и не заметили URL: https://zen.yandex.ru/media/proautobiz/kak-pod-bokom-u-rossii-vyrostureckii-avtogigant-a-my-i-ne-zametili-5ffdb190d65541786b61d4b0

6. Варшавский A.E. Проблемы многоплановости задачи ускорения научнотехнологического и инновационного развития России // Вестник ЦЭМИ PAH. 2018. Выпуск 1. URL: https://cemi.jes.su/s111111110000122-7-1/ DOI: $10.33276 / \mathrm{S} 0000122-7-1$

7. Варшавский А.Е., Дубинина В.В. Мировые тенденции и направления развития промышленных роботов // МИР (Модернизащия. Инноващии. Развитие). 2020. Т.11. №3. С. 294-319.

8. Перспективы Индустрии 4.0 и цифровизации промышленности в России и мире. Аналитический отчет. URL:

http://json.tv/ict_telecom_analytics_view/perspektivy-industrii-40-itsifrovizatsii-promyshlennosti-v-rossii-i-mire-20180312123158

9. Россияне автоматизировали регистрацию проституток в Германии. URL: http://www.cnews.ru/news/top/2018-10-

11_rossiyane_avtomatizirovali_registratsiyu_seksrabotnikov

10. Варшавский А.Е., Винокурова Н.А., Кочеткова Е.В. Представления ученых о том, какие профессии являются наиболее подходящими для их детей и внуков // Народонаселение, 2020, т.23, №1, c.119-134. DOI: 10.19181/population.2020.23.1.10

11. Матыцин М.С., Ершов Э.Б. Исследование дифференциации российского населения по реальным доходам // Экономический журнал ВШЭ. 2012. Т.16, №3. С. 318-340.

12. Суворов А.В. Доходы и потребление населения: макроэкономический анализ и прогнозирование. М.: МАКС Пресс, 2001

13. Шевяков А.Ю., Кирута А.Я. Неравенство, экономический рост и демография: неисследованные взаимосвязи. - М.: М-Студио, 2009. 
Вариавский А.Е. Об актуальных проблемах экономического развития.., стр. 22-37

Varshavsky A.E. On the current problems of economic development..., pp. 22-37

14. Овчарова Л.Н., Пишняк А.И., Попова Д.О., Шепелева Е.В. Изменения в доходах и потреблении российских домашних хозяйств // SPERO. 2013. № 18. С.7.

15. Колеников С.О., Айвазян С.А. Уровень бедности и дифференциация населения России по расходам. Научный доклад 01/01. Российская программа экономических исследований 2001.

16. Варшавский A.E. Чрезмерное неравенство доходов - проблемы и угрозы для России // Социологические исследования. 2019. Том 10. №19. С. 52-61 DOI: $10.31857 / \mathrm{S} 013216250006136-2$

17. Миллионы псу под хвост: сколько денег тратят в России на бездомных животных. URL: https://politexpert.net/131443-milliony-psu-pod-khvost-skolkodeneg-tratyat-v-rossii-na-bezdomnykh-zhivotnykh

18. Ясакова Е. Неприютная ситуация: во сколько государству обойдется содержание бездомных животных. URL: https://iz.ru/1043958/ekaterinaiasakova/nepriiutnaia-situatciia-vo-skolko-gosudarstvu-oboidetsia-soderzhaniebezdomnykh-zhivotnykh/

19. На питание $0.01 \%$ беспризорных собак государством выделяется в два раза больше денег, чем на детей. URL: http://www.animalsprotectiontribune.ru/nnnn694.html

20. Арефьев Н.В. Детям войны, ровесникам Гагарина, снова отказано // Советская Россия. Выпуск от 25.01.2020.

21. Латухина K. «Сергей Иванов: Мне моего влияния вполне достаточно» // Российская газета. Выпуск от 01.10.2013.

22. Варшавский A.E. Пространственное неравенство и центростремительное движение населения России: угрозы экономической, научнотехнологической и национальной безопасности // Научно-практический журнал "Конщепции". 2018. №1 (37). С.3-27.

23. Варшавский A.E. Ускоренная деиндустриализация Москвы: основные проблемы и последствия // Научно-практический журнал "Концепции". 2018. №1(37). C.79-96.

24. Варшавский A.E. Чрезмерное неравенство: угрозы, пути решения проблемы // Научно-практический журнал "Концепции". 2016. №1(35). С.83-93.

25. Варшавский А.Е. Анализ влияния неравенства доходов на музыкальное искусство // Журнал Новой экономической ассоциации, 2020. № 2(46). С.118-137.

26. Микушина T.Н. Секреты музыки сб. статей / Сост. Т.Н. Микушина, Е.Ю. Ильина. — Омск: Издательский Дом «СириуС», 2017.

27. Частоты вибраций тела и органов человека. URL: https://econet.ru/articles/132316-chastoty-vibratsiy-tela-i-organov-cheloveka

28. Варшавский A.E. Проблемные инновации: риски для человечества. М.: ЛЕНАНД, 2014.

29. Варшавский A.E. Развитие человеческого капитала: уроки коронавируса - недопустимость проблемных инноваций в управлении // Научные труды $B Э O$ России. 2020. №3(223). C.228-236. DOI:10.38197/2072-2060-2020-223-3-228-236 
30. Фурсенко A. Разработаны критерии результативности работы научных организаций. URL: https://www.mk.ru/politics/article/2008/11/25/11331-andrey-fursenkorazrabotanyi-kriterii-rezultativnosti-rabotyi-nauchnyih-organizatsiy.html

31. Инновационный менеджмент в России: вопросы стратегического управления и научно-технологической безопасности / Руководители авт. колл.

В.Л.Макаров, А.Е.Варшавский. М.: Наука 2004. URL:

http://www.cemi.rssi.ru/publication/newbooks/innmenedg/m-v_inn.pdf

32. Наука и высокие технологии России на рубеже третьего тысячелетия (социально-экономические аспекты развития) / Руководители авт. колл. В.Л. Макаров и А.Е. Варшавский. - М.: Наука, 2001. URL: http://www.cemi.rssi.ru/publication/newbooks/science/m-v_sci.pdf

33. Затраты на охрану здоровья в странах ОЭСР, 2019. URL: http://www.demoscope.ru/weekly/2020/0859/barom02.php

34. Варшавский А.Е., Яркин А.П. Ведущая роль ЦЭМИ АН СССР в организации, управлении и разработке комплексных программ научнотехнического прогресса // Экономика и математические методы. 2018. T.54. № 3. C. 68-89.

\title{
ON THE CURRENT PROBLEMS OF ECONOMIC DEVELOPMENT, INEQUALITY AND ITS IMPACT ON OUR LIVES
}

\author{
Varshavsky A.E.
}

The paper considers issues related to the deepening problems of socioeconomic, scientific and technological development of Russia as a result of the crisis caused by the coronavirus epidemic, including problems related to national security. The necessity of improving the economic policy and the credit and financial system is shown. Special attention is paid to the problems of significant deindustrialization, as well as problems related to digitalization. Microeconomic issues are considered, first of all, the problems of excessive income inequality and spatial inequality, the resources that can be obtained as a result of income redistribution are estimated, and the negative impact of income inequality on the musical art is shown as an example. The necessity of improving the management as well as prevention of the inadmissibility of problematic (questionnable) innovations, including ones in the fields of education, science and health, as well as the need to develop an indicative planning system is shown. 